\title{
The expanding impact of technology on underground geomechanical mine design and operations - advances, limitations and future needs
}

WF Bawden Mine Design Engineering, Canada

\begin{abstract}
The data-limited nature of mining geomechanics problems often result in high degrees of uncertainty in design analyses. Greater uncertainty results in the application of higher safety factors and resulting costs. While empirical design methods, instrumentation and particularly numerical modelling have undergone transformational change over the past 35-40 years, with the exception of the introduction of scanning technologies, there has been very little advance in geotechnical data collection techniques. The result is that our modelling capabilities now vastly exceed our ability to characterise fractured rock masses and parameterise design models. The failure to recognise the high level of inherent uncertainty in many, if not most, geomechanical analyses can arise as an unforeseen fatal flaw in high level corporate decision-making. This paper provides an incomplete review of advancements in geomechanical mine design over the past 40-odd years, an assessment of the present status and a view of where significant advances are required.
\end{abstract}

\section{Introduction}

Advances in technology have driven advances in mining since the invention of fire setting for rock fragmentation in prehistoric time, through the development of modern explosives, mechanical drilling and cutting, introduction of mobile fleets, etc. Geomechanics as a formal discipline developed relatively late in the storied history of mining. A series of disastrous accidents associated with large rock engineering projects in the 1950s and 1960s, (Vaiont Dam, Italy; Malpasset Dam, France; Colebrook Mine collapse, South Africa), led to the realisation that our ability to engineer large structures in/on fractured rock masses was inappropriate for the scale of structures being contemplated. The science of rock mechanics effectively emerged out of this societal need. The mining field has advanced dramatically through this period with the largest open pits now reaching or exceeding $1 \mathrm{~km}$ depth and the deepest underground mines reaching 3 to $4 \mathrm{~km}$ depth. The application of geomechanics to mine design has equally advanced dramatically and is critical to both safety and economic success in modern mining. This paper reviews historical advances in geomechanical mine design and looks ahead at where future developments may lead us and what hurdles stand in the way.

\section{Historical developments}

The following is a brief and incomplete history of technological developments in geomechanics and its adaption by and impact on underground mining.

\subsection{Rock mass classification}

To quote Dr Hoek (1980):

"If one is fortunate to have an engineer on staff who has designed and supervised the construction of underground excavations in similar rock conditions to those being considered, design considerations can be taken with some degree of confidence. 
On the other hand, where no such experience is readily available, what criteria can be used to check whether one's own decisions are reasonable? How does one judge whether the span is too large, or whether too many or too few rockbolts have been specified?

The answer lies in some form of classification system which enables one to relate one's own set of conditions to conditions encountered by others. Such a classification system acts as a vehicle which enables a designer to relate the experience on rock conditions and support requirements gained on other sites to the conditions anticipated at his own site."

Dr Hoek sagely advised this author (in his youth) not to discount the importance of empirical engineering in geomechanics, advice that proved prescient. A brief history of the developments in rock mass classification follows.

The earliest attempt at classification was by Dr Karl Terzaghi, generally considered the father of modern geomechanics. Terzaghi was interested in better prediction of loading on steel set tunnel support. Terzaghi, who had a geology background, presented very clear definitions of rocks with different structure (e.g. intact, moderately jointed, blocky etc.), and their implications for engineering. Lauffer (1958) introduced the concept of stand-up time and noted that stand-up time for an unsupported excavation can be related to the quality of the rock mass in which the span is excavated. Deere (1964) introduced the rock mass quality index (RQD). RQD was an attempt to more quantitatively assess rock mass quality from standard drill core. Attempts were also made to relate RQD directly to tunnel support. The first truly comprehensive rock mass classification systems were developed in the 1970s (Barton - Q-system (1974); Bieniawski - rock mass rating (RMR) system (1973; 1976)). These systems were developed largely from civil engineering databases but have gradually been adopted in mining. Both systems generally incorporate earlier contributions such as RQD etc. A modification of the RMR system for caving mines was developed by Laubscher (1977). The most recent rock mass classification system to achieve wide acceptance is the geological strength index (GSI) (Hoek et al. 1995). This system was initially introduced to overcome limitations with the use of the RMR system to derive generalised Hoek-Brown rock mass constitutive parameters for very poor rock masses. GSI can be directly calculated from modified $Q^{\prime}$ or RMR' classifications or can be estimated directly from the chart shown in Figure 1. Rock mass classification remains the foundation of most mining geomechanics analyses.

\subsection{Empirical design methods}

The advent of mechanised, high-productivity blasthole and long hole stoping methods led to the need for improved stope, pillar and support design methods. The stability graph method (Hoek et al. 1995; Potvin 1988) provided a methodology to address the design of open stopes in underground mines (Figure 2). In this method, the site geomechanics ( $Q^{\prime}$ classification modified for mine-induced stress, critical structure and stope geometry) is plotted on the vertical axis and the stope wall geometry (represented as hydraulic radius) is plotted on the horizontal axis. Documented historic open stope case studies allow definition of stable versus unstable zones, which planned future stope behaviour can be assessed against. Modifications to the original stability graph include the addition of probability of failure (Mawdesley et al. 2001) and dilution estimation (equivalent linear over-break slough (ELOS); Clark \& Pakalnis 1997).

An empirical critical span curve for back stability in cut-and-fill mines was published and later expanded for opening design in weak rock masses (Brady et al. 2005). An empirical design span curve was also developed for underhand cut and fill mining (Pakalnis et al. 2005).

Pillar design originated as empirical pillar design formulas developed in the coal industry from studies such as that by Salamon and Munroe (1967) and others. Equation 1 shows a typical pillar strength formula. Similar pillar studies were conducted in hard rock environments (Hedley \& Grant 1972). The hard rock pillar databases were re-analysed by Lunder and Pakalnis (1997), who developed the confinement pillar stability graph (Figure 3). 


$$
F S=\sigma_{P S} / \sigma_{P}=\frac{K H^{a} w_{p}^{b} p(1-e)}{\gamma z}
$$

where:

$$
\begin{aligned}
& \sigma_{p}=\text { pillar strength. } \\
& K \quad=\text { strength of a unit cube of coal. } \\
& a, b=\text { constants. } \\
& \sigma_{p s}=\text { average pillar load. }
\end{aligned}
$$

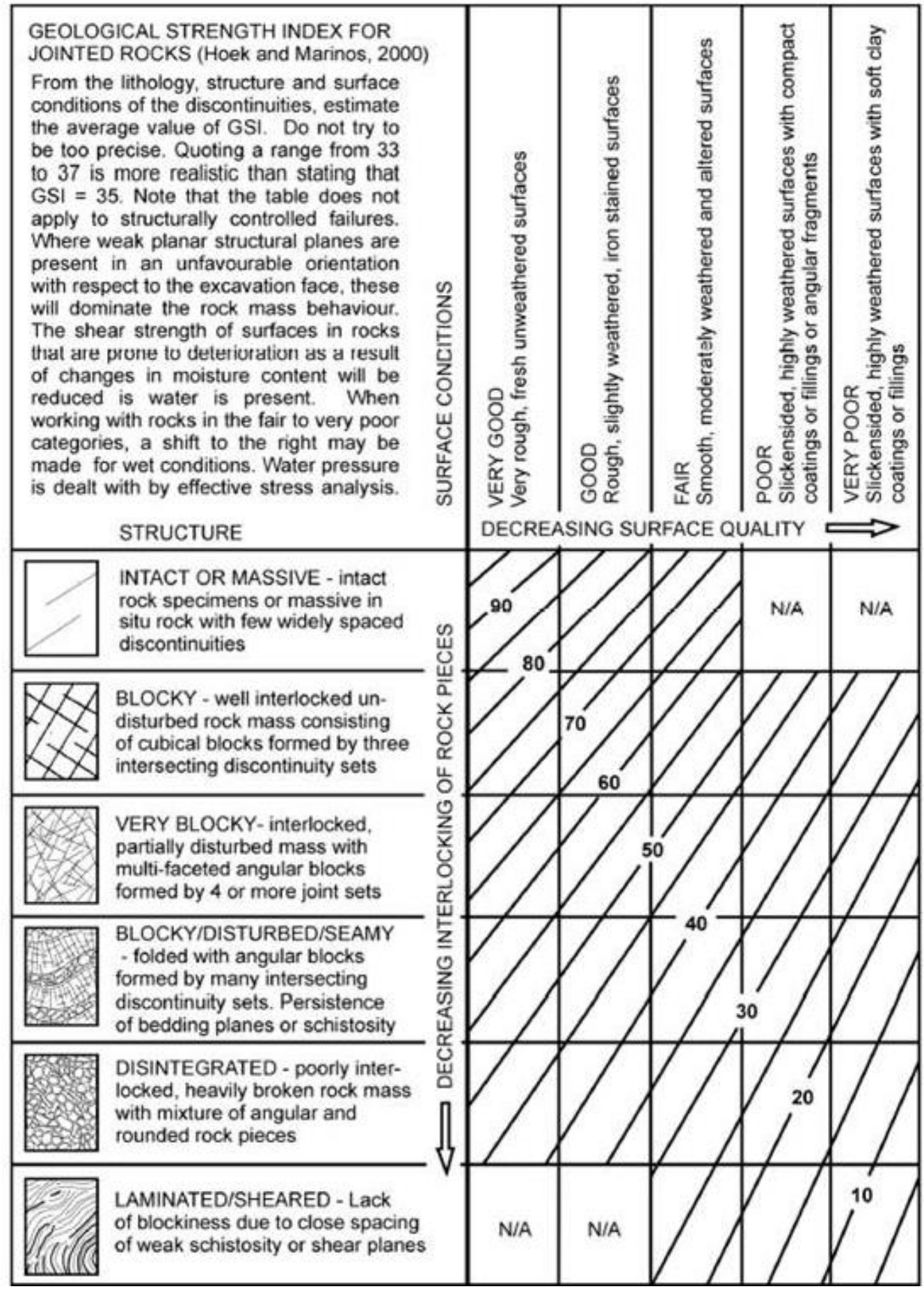

Figure 1 Geological strength index chart (Hoek 2007) 
Ground support design was initiated as empirical rules of thumb, e.g. Corps of Engineers. These rules of thumb were later supplanted by numerous ground support design charts, of which perhaps the best known is that of Grimstad and Barton (1993) (Figure 4). Deep secondary support, e.g. cable bolt, was initially derived as part of the stability graph design work and was expanded on in 'Cablebolting in underground mines' (Hutchinson \& Diederichs 1996).

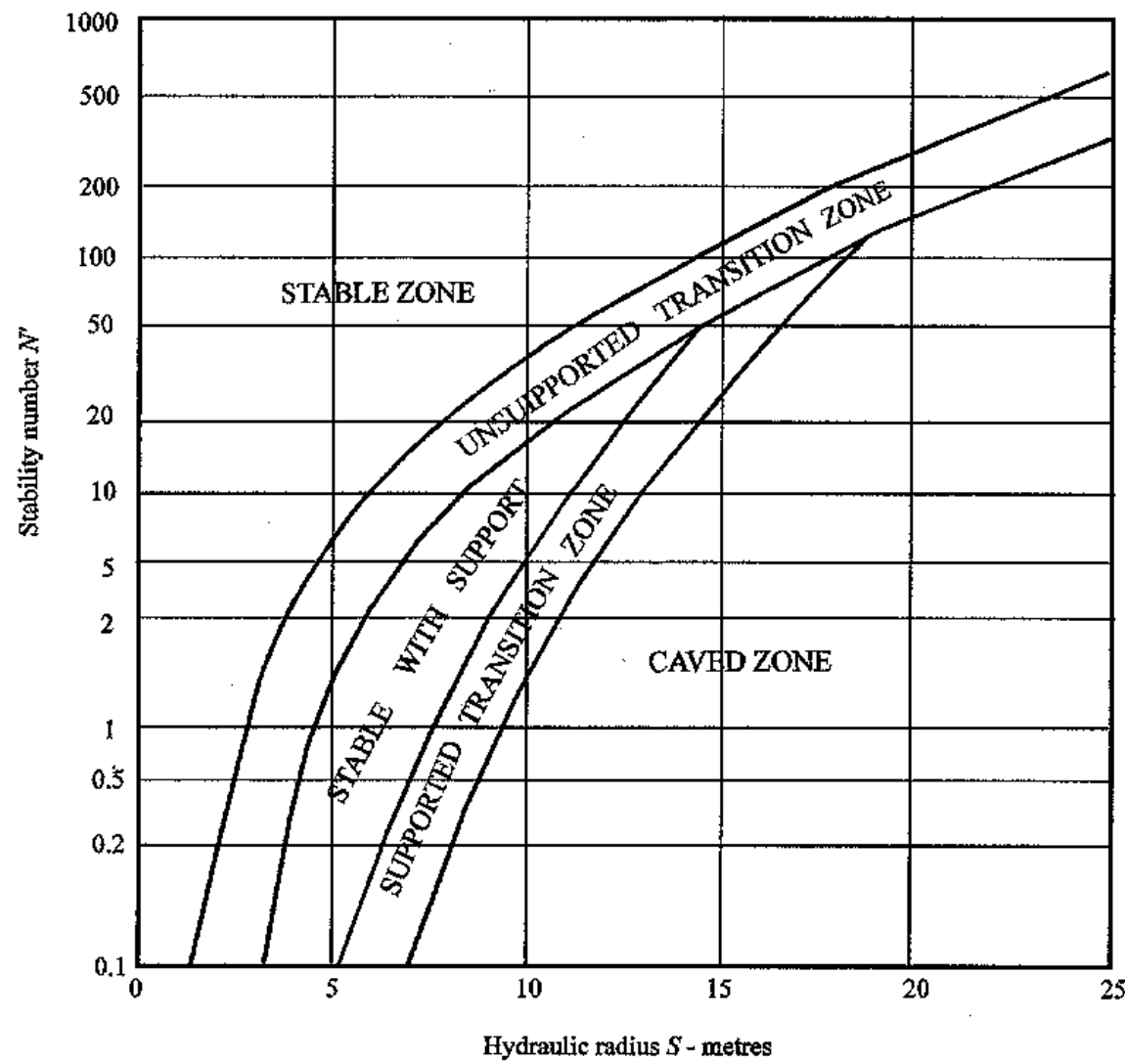

Figure 2 Open stope stability graph (Hoek et al. 1995; Potvin 1988)

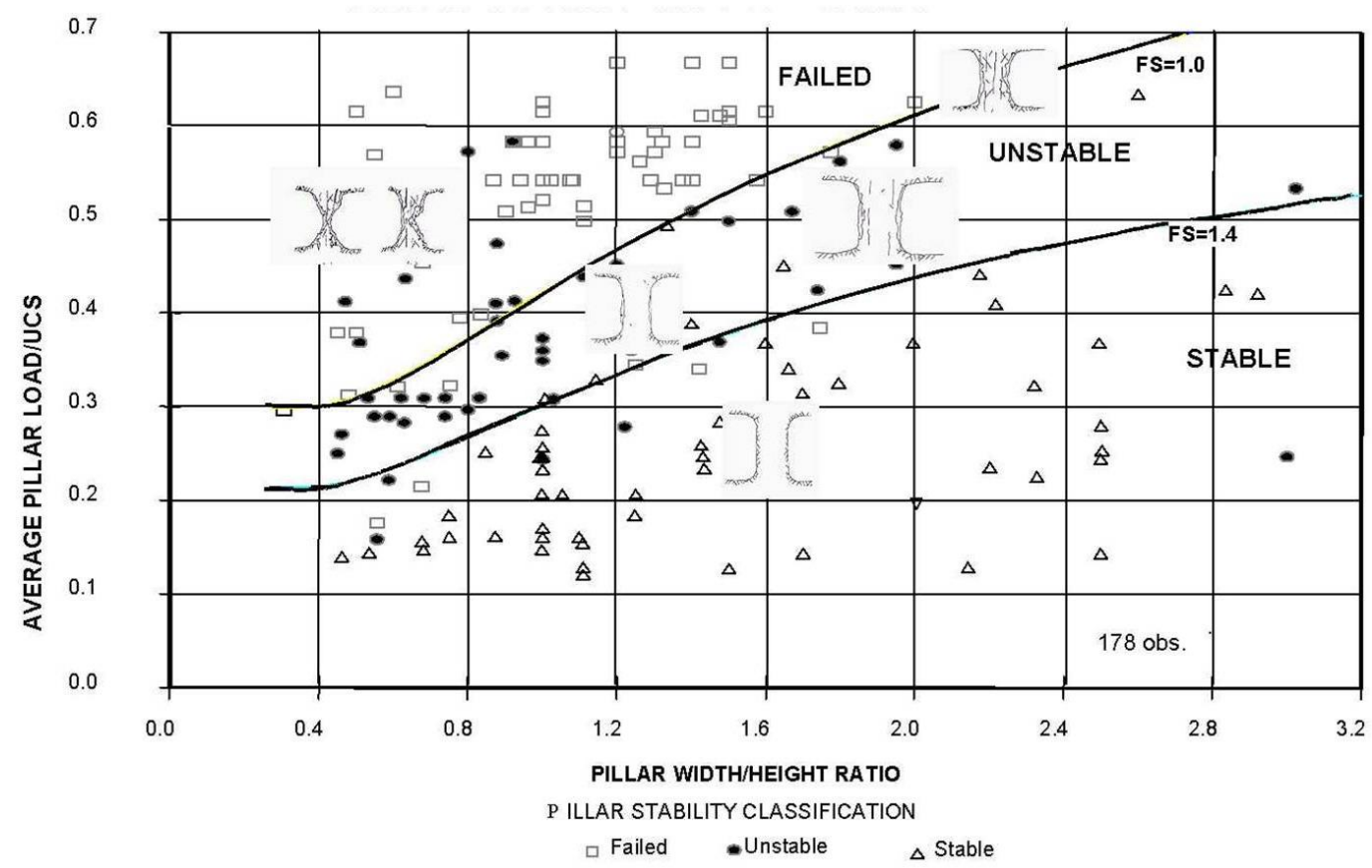

Figure 3 Confinement pillar stability graph (Lunder \& Pakalnis 1997) 
In block cave mining, the classical empirical caving curve (Laubscher 1977; 1984) served, until recently, as the definitive caving design guideline. This empirical design is now being complimented with sophisticated numerical analysis techniques.

The previous empirical tools have served the industry well for the past 30 to 40 years and remain in wide use internationally. In all cases, empirical design methods should be field fitted (calibrated) for the specific site conditions where suitable data is available to do so. This is generally only possible for relatively mature mines. As mining moves to much greater depths $(>1-2 \mathrm{~km})$, where rock mass behaviour is likely to be stress dominated rather than structurally dominated, new tools and approaches will be required.

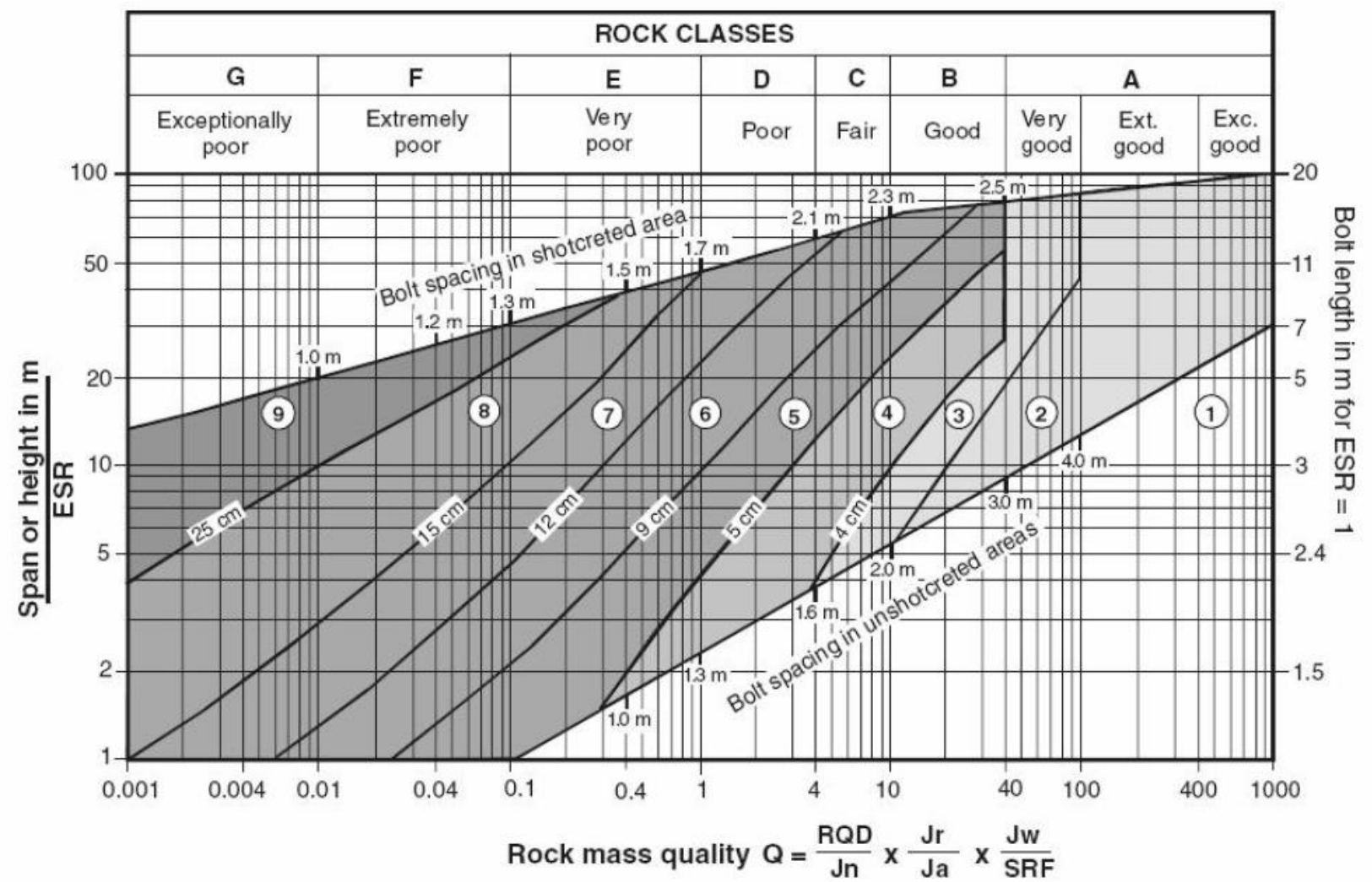

\footnotetext{
1) Unsupported

2) Spot bolting

3) Systematic bolting

4) Systematic bolting, (and unreinforced shotcrete, $4-10 \mathrm{~cm}$ )

5) Fibre reinforced shotcrete and bolting, $5-9 \mathrm{~cm}$
}

REINFORCEMENT CATEGORIES:

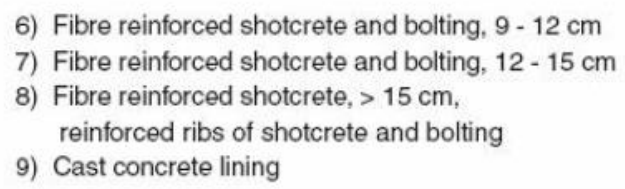

Figure 4 Empirical rock reinforcement chart (Grimstad \& Barton 1993)

\subsection{Instrumentation}

Prior to the 1980s, very limited instrumentation was used in underground mining. The development of instrumentation designed to survive the extremely harsh underground environment, combined with the much greater focus on safety in mining, has led to a significant increase in the use of conventional instrumentation. Rockburst problems have plagued mining for many decades and naturally become more problematic as mines move to greater depths. Sophisticated seismic monitoring systems are now routinely available and are demanded for any mine experiencing (or expected to experience) mine-induced seismicity.

One of the major instrumentation developments from the 1990s was the cavity monitoring survey (CMS) technology. The CMS technology was rapidly adapted by the industry, and CMS surveying of all open 
stopes, providing accurate as built geometry, is now the accepted standard, providing the ability to assess unplanned dilution and ore loss on a routine basis.

\subsection{Numerical modelling}

Comprehensive numerical modelling of underground mines is a relatively recent innovation. Prior to the development of powerful personal computers, numerical modelling was not a part of standard mine design. The earliest attempt at simulating mine-induced stresses was conducted in South Africa using an electrical analogue approach. With the development of modern computers this was replaced by numerical methods, initially using the displacement discontinuity (DD) technique (Malan 2015). This method was adapted by CANMET for the steep tabular orebodies common in eastern Canada and by the mid-1980s this software, combined with 2D boundary element models, (e.g. code published by Hoek \& Brown 1980), began to gain traction as analysis tools (Figure 5 ). As computing speed and memory capabilities accelerated through the 1990s, 3D boundary element software became practical, greatly increasing the utility of numerical modelling as an analysis and forward design tool for underground mining. At that time, largely due to computer run time and memory restrictions, models were restricted to linear elastic behaviour. Most such modelling efforts were conducted by expert consultants with very little modelling being conducted directly at the mine site, a situation that remains common today.

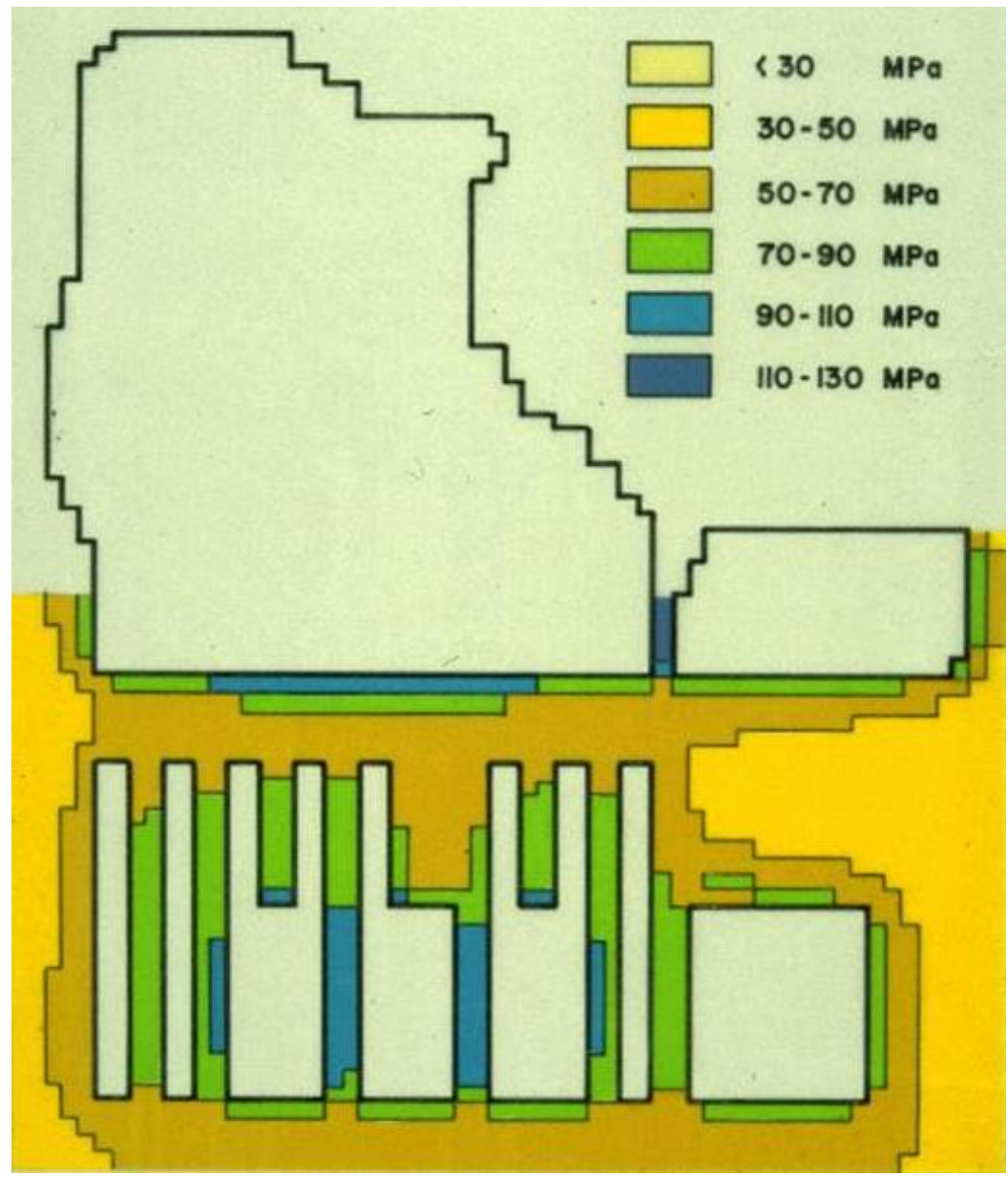

Figure 5 1980s numerical model of longitudinal mine section showing transverse stoping below a mined block using a displacement discontinuity model 


\section{$3 \quad$ Present status and future directions}

\subsection{Data collection}

A sound geotechnical database has always formed the baseline for any geomechanical analysis or mine design. This data has traditionally been derived from geotechnical logging of exploration core supplemented with select, dedicated geotechnical holes. Once underground development becomes available, the geotechnical database is enhanced using techniques such as line mapping. Both core logging and line mapping are arduous and time-consuming tasks that require highly trained personnel who must remain focused and diligent in performing these tasks. Subsequent analyses are only as strong or as weak as the underlying geotechnical database. No matter how good the geotechnical database, it is important to remember that geomechanical analyses always fall into the data-limited category, i.e. the database represents a miniscule sampling of the field scale rock mass.

In many underground operations today, development headings are sprayed with shotcrete almost as soon as they are developed, offering very limited opportunity for mapping. This is a serious issue for geomechanical mine design studies that rely on field data. Modern scanning systems, photogrammetric or laser scans, offer the opportunity to obtain this critical data without seriously interrupting critical path development work. While these scanning techniques permit the development of the required structural data, i.e. strike, dip, persistence, they provide little to no information on structural surface characteristics, i.e. roughness, alteration, that must then be derived by other means, e.g. mapping, drill core etc. This author is not aware of any other new technologies presently being developed that will alter the fundamental nature of this critical work.

\subsection{Instrumentation}

While new and/or improved instruments are occasionally introduced to the market, the main suite of practical instruments, e.g. borehole extensometers, closure meters, piezometers, inclinometers, stress cells etc., has remained relatively static. The recent step change in instrumentation functionality lies in the methods of data collection and transmission. Until very recently, instrumentation data either had to be collected manually using hand held readout units, local dedicated loggers or the instruments had to be hard wired back to data acquisition units normally housed in a secure area such as a refuge station. Both methods of data transmission/acquisition are plagued with practical problems. Manual readings require a technician to be available to routinely traverse the mine to collect the data. Operational pressures often result in far from optimal data recording (Figure 6). If instrumentation is hardwired back to the data acquisition unit it becomes much more expensive (electrician time to pull wires etc.) and is susceptible to equipment damage to the wires. In fact, such systems normally suffer significant downtime due to equipment damage and, hence, there are losses of potentially critical data. 


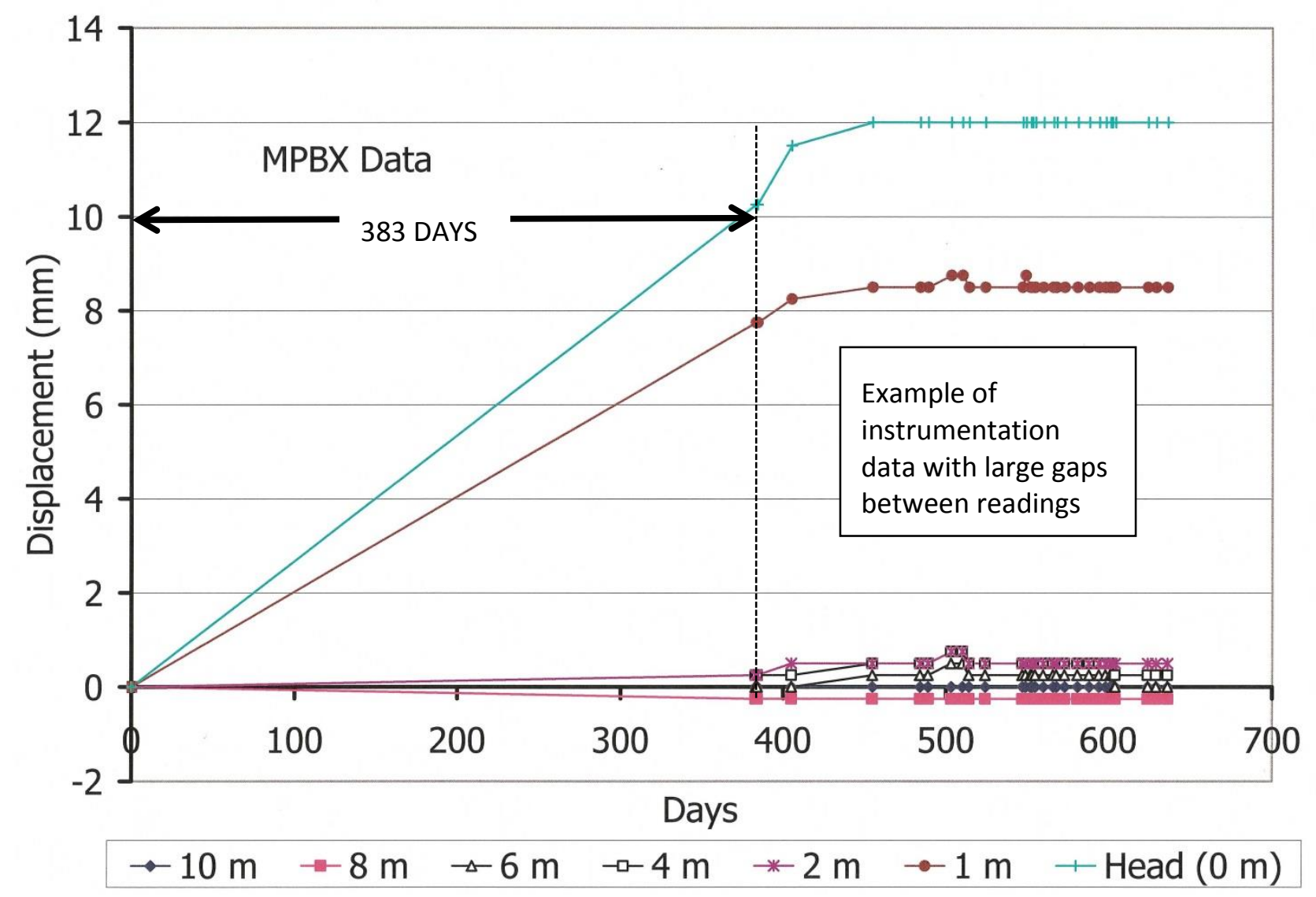

Figure 6 Instrumentation data not suitable for model calibration

Recent step change advances in wireless data communication eliminate the data acquisition/transmission problems discussed above. There are many competing entities, e.g. Becker Varis; PBE Group; Kutta technologies (Moore 2014). Most of these systems are focused on voice and video transmission requiring broadband frequency transmission that results in numerous challenges, e.g. short transmission distances, high power requirements, etc., in the underground environment. For simple data transmission, i.e. not including voice and video, a system not requiring line of sight antennas and capable of long life battery operation is better suited to the dynamic underground environment. Such systems should be easily deployed and maintained, should not require electrical department support, should record and transmit data in near real time, and once deployed should act as a self-identifying, self-healing mesh network. Data should be transmitted in a fully wireless mode to a gateway connected directly to the mine communications system, e.g. fibre optic, leaky feed etc., and then to a dedicated central server. Through the internet, the data can then be available in real time to anyone with access to the system. Such comprehensive, real-time data acquisition is critical for safety and for calibration of complex modern numerical models. An example of such technology is the Newtrax MineHop system (Figure 7). This system provides a back bone that, in addition to monitoring geotechnical instrumentation, can facilitate tracking of staff and equipment, performing collision avoidance (assuming tracking), equipment systems monitoring, ventilation on demand and air quality monitoring.

Mine wide microseismic monitoring systems require high bandwidth transmission and for this reason are normally hard wired in. Such systems normally suffer from periodic loss of sensors due to equipment damage. The alternate is to provide significant built-in intelligence at each sensor to reduce the required data bandwidth, an issue fraught with both high cost and technological challenges with the automated data interpretation.

In the future, the ideal would be to incorporate microseismic sensors with conventional instruments with either greatly improved intelligence at each sensor, or with a next generation high bandwidth, low power 
consuming underground wireless transmission capability. Advanced chip technologies may make this a possibility in the coming years as companies focus on hybrid low power and high bandwidth on-demand systems that are specifically designed for the underground environment. Generic solutions that come from other markets, e.g. health care, construction, open pit mining etc., are often ill-suited to underground. Purpose built systems that are designed for the underground mining industry are often the only ones that survive in today's competitive market.

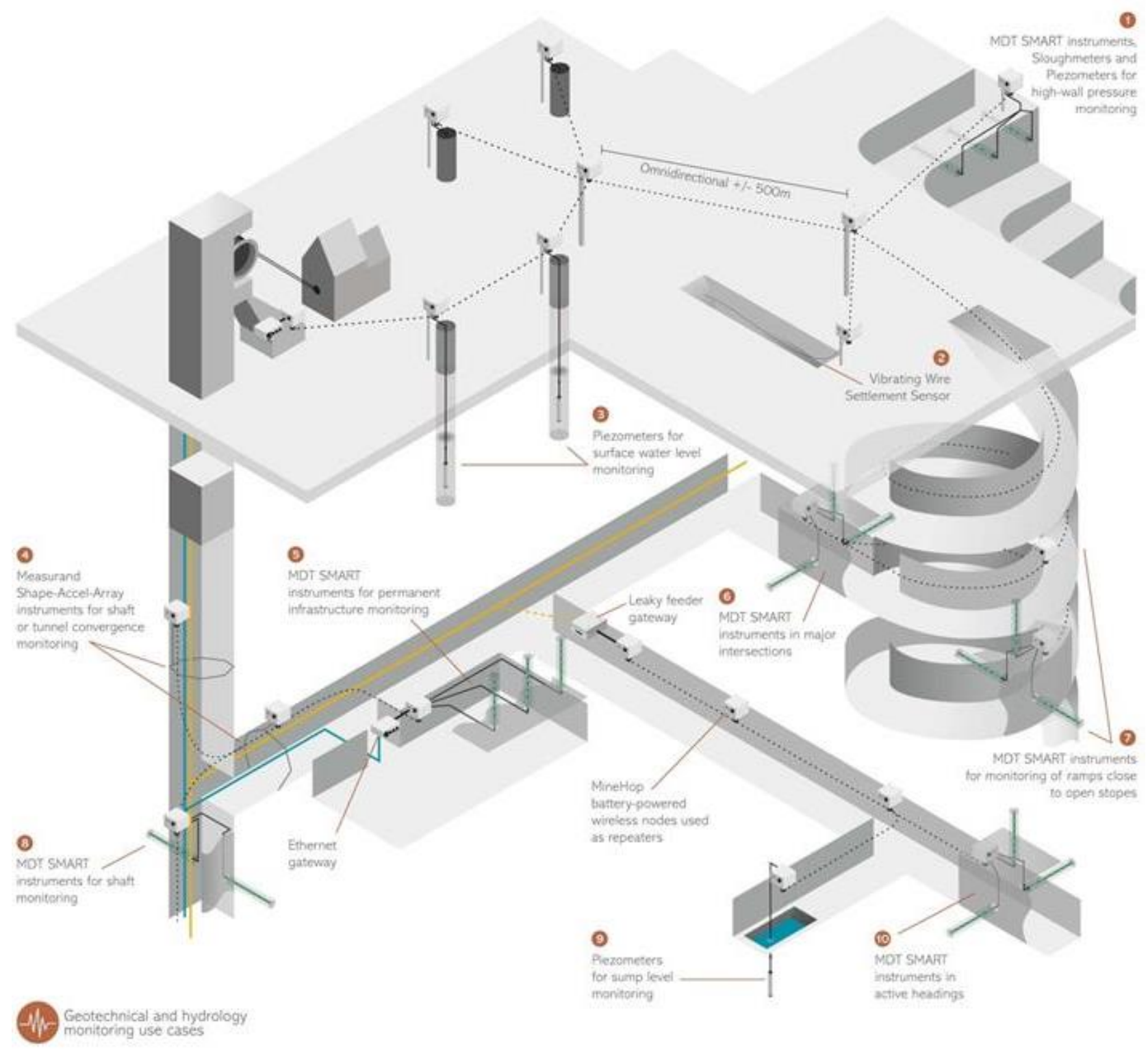

Figure 7 Newtrax MineHop Wireless Telemetry schematic (figure courtesy of Newtrax)

\subsection{Numerical modelling}

As noted earlier, following modest beginnings in the mid-1980s numerical modelling has experienced exponential growth, tightly aligned with the exponential growth in computational power, speed and memory. Today a plethora of models (FEM, BEM, DEM, PFCs etc.) are commercially available. Almost all numerical models today have 3D nonlinear capability, reasonably user-friendly interfaces and superb graphics. This has resulted in significant contributions to the industry but also with certain problems.

The way in which stress and strain are related in a material under load is described qualitatively by its constitutive behaviour. A variety of idealised constitutive models have been formulated for various 
engineering materials, which describe both the time-independent and time-dependent responses of the material to applied load. These models describe responses in terms of elasticity, plasticity, viscosity and creep. For any constitutive model, stress and strain, or some derived quantities such as stress and strain rates, are related through a set of constitutive equations. In elasticity, the constitutive formulation for a homogenous elastic model requires two independent input parameters, $(E, \mu)$, while a transversely isotropic material (common in many rock types), requires five independent input parameters $\left(E_{1}, \mu_{1}, E_{2}\right.$, $\mu_{2}, G_{2}$ ). A fully anisotropic elastic material would require 21 independent input parameters (Brady \& Brown 1985).

Rocks and fractured rock masses are extremely complex materials. While intact rock behaviour is always important at some level, fractured rock mass behaviour is generally controlled by the dominant, local fracture systems. The resulting behaviour may be isotropic or anisotropic. There is no universally accepted theoretical constitutive behaviour for fractured rock mass behaviour. For modelling purposes, fractures can be smeared into the continuum constitutive behaviour using empirical methods such as GSI, incorporated using ubiquitous joint models or explicitly modelled. In the latter cases, each joint set must also be assigned a constitutive model and appropriate strength and stiffness parameters.

The fact that no generally accepted, theoretically based, constitutive law exists for fractured rock mass behaviour introduces uncertainty into non-linear modelling. Uncertainties revolve around the following:

- The widespread use of the generalised Hoek-Brown formulations where material property inputs rely on rock mass classification with their inherent uncertainty.

- The need to define cohesive, frictional and stiffness properties for multiple discontinuity sets.

- Uncertainty in far field stress input.

- Very high uncertainty with assumptions concerning post-peak behaviour.

The complexity of numerically simulated constitutive behaviour depends largely on the assumptions made with respect to elasticity versus plasticity and, where non-linear models are selected, the representation of post-peak behaviour, e.g. perfectly plastic versus strain weakening behaviour. As mentioned above, elastic models are the most simplistic to parameterise. With non-linear modelling, not only peak strength but post-peak failure constitutive parameters must be assigned, significantly increasing the difficultly/uncertainty in parameterising models.

The trend in numerical modelling has been toward more and more complex models, including plasticity (perfectly plastic, post-peak strain softening/hardening, dilatency), discrete fracture networks, fracture nucleation and propagation, simulated seismicity, etc. The generalised Hoek-Brown and Mohr-Coulomb failure criteria, however, remain the most widely accepted and used criteria for intact rock and fractured rock mass behaviour and are incorporated in virtually all commercial complex non-linear models. Recent approaches to address the constitutive behaviour of fractured rock masses include the development of particle flow code (PFC) models and the numerical representation of synthetic rock masses. Most 3D non-linear codes allow incorporation of ubiquitous jointing and discrete structures; however, the pervasive application of numerous discrete structures in a single mechanical model is typically limited (for most commercial software packages) by computational issues and run-time inefficiencies. Computational limitations place significant restrictions on using these methods for large-scale mine models.

The degree of complexity incorporated in a numerical model must be justified by the quality and quantity of geomechanical data available for material parameterisation, the degree of confidence in assumed boundary conditions, and the rigor of calibration (which of course is also reliant on data quality and quantity). Elastic models are very simplistic. They are simple to execute and interpret and in many cases still provide reasonable output which is sufficient for purpose. Once one embarks on non-linear modelling, the level of sophistication or complexity increases on all levels. Most critical in this, however, is the substantial increase and sophistication of required input data. In all non-linear models, with the exception of PFC and synthetic rock mass models, post-peak behaviour is characterised and parameterised through the 
application of various assumptions, rules of thumb, empirical and semi-empirical methods. The difficulties in deriving reliable post-peak parameters are discussed in Bawden (2010) and represent a major source of uncertainty.

Geomechanical analyses in mining always fall into the 'data-limited' category (Figure 8; Holling 1978), and in many cases, our analyses are severely data-limited. In the present and foreseeable situation, overcoming these data limitations, in practical applications of geomechanical engineering, is completely unrealistic. Data-limited problems pose dangerous restrictions on the reliability of complex 3D non-linear numerical simulation results. It is noted that all existing non-linear models contain simplifications and assumptions which reduce the actual number of required input parameters. These simplifications and assumptions, however, do not negate the inherent uncertainties, and in some cases, these simplifications and assumptions actually introduce additional uncertainties. The question is then how to pragmatically address this situation.

The uncertainties discussed above all relate directly to the data-limited nature of geomechanics problems. The large number and high uncertainty levels surrounding required input parameters mean that if models cannot be highly constrained, varying the numerous input parameters can result in substantial variance in predictions from the same model. This uncertainty, generally not recognised by mine management and sometimes neither by practitioners, can only be constrained by rigorous model calibration. Calibration can be qualitative, e.g. overlaying seismic, numerical stress and field damage mapping data to calibrate yielded versus intact zones; or quantitative, e.g. directly comparing location specific model predicted stress and deformation values to field instrumentation results, as discussed in Crockford et al. (2015). Both forms of calibration are of great value in constraining model input parameters. Quantitative calibration represents the 'holy grail', but is very difficult to achieve. Crowder et al. (2006) provide an example of an attempt at quantitative calibration and discuss the implicit problems. Perhaps most critically, quantitative calibration requires that instrumentation be installed sufficiently early such that the complete stress-deformation development is captured without significant gaps. This also needs to be done at as many locations as possible in order to capture mine-scale rock mass response and locational differences in behaviour. For these reasons, qualitative calibration is often the best that can be achieved in mine-scale modelling applications.

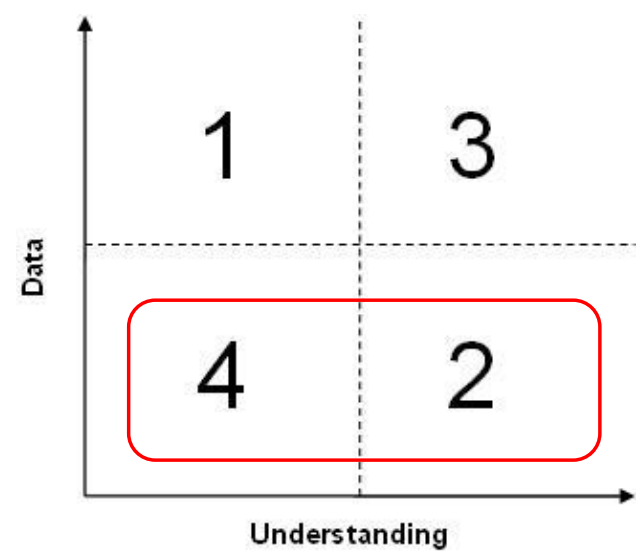

Figure 8 Data-limited problems - mining geomechanics in the square

Even with a calibrated model, uncertainty remains since (i) differing adjustments of the varying input parameters can potentially result in the same output, in which case it may be unknown as to which input values are correct; and (ii) uncertainty that, with forward modelling, field conditions will be sufficiently similar to the calibrated case that the same input parameters apply (i.e. unknown unknowns).

Some practitioners suggest that only sophisticated inelastic models should be used in virtually all numerical simulations. As a recent example, Vakili et al. (2014) discuss anisotropy and complexity in rock masses (Figure 9) and make suggestions as to the appropriate level of modelling that should be applied. 


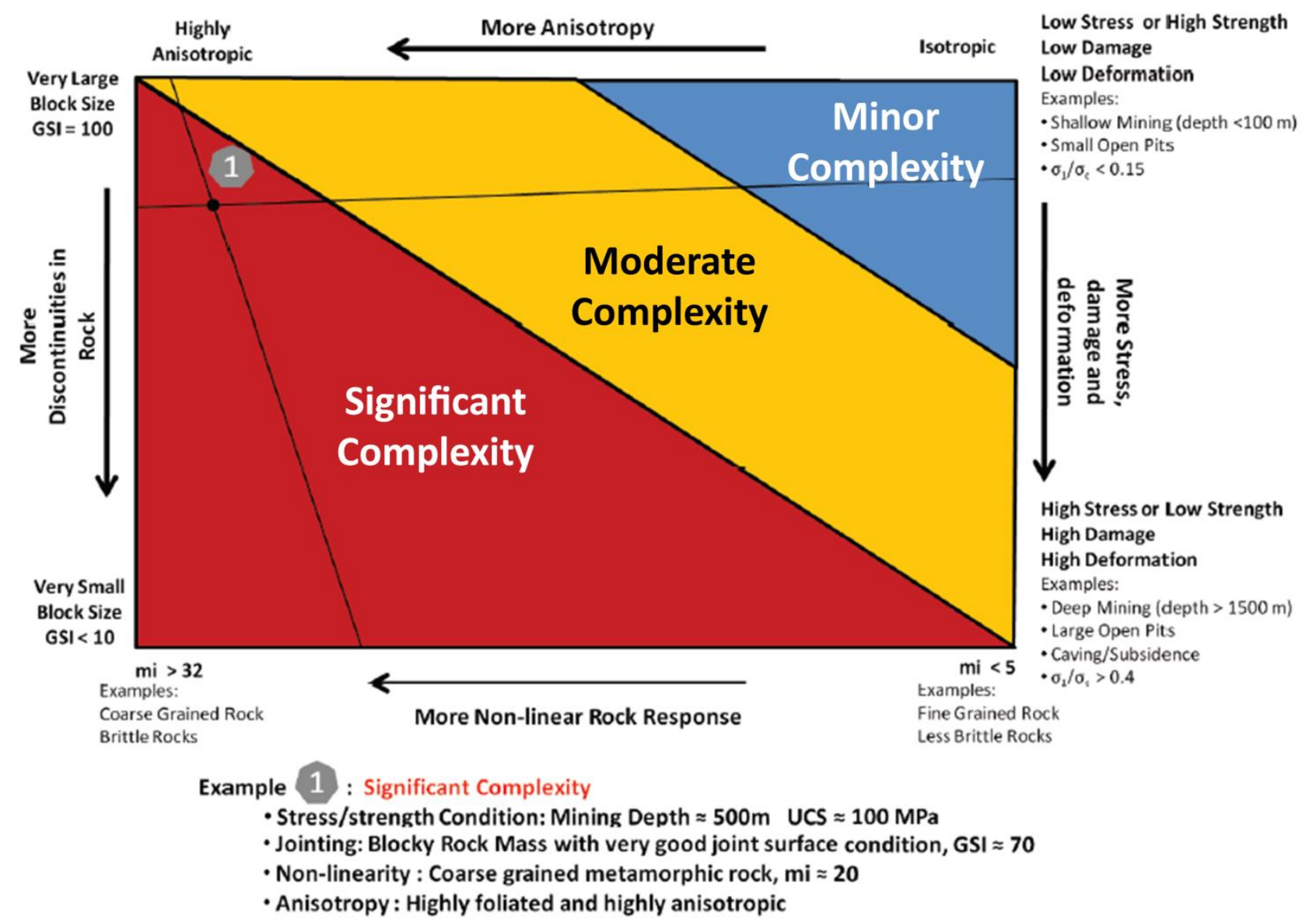

Figure 9 A matrix of degree of complexity in various geotechnical conditions (modified from Vakili et al. 2014)

In their guideline for the selection of appropriate analytical methods, Vakili et al. (2014) suggest that for moderate complexity:

"Empirical methods should be applied with great caution.

If no calibration data exist, application of elastic or implicit inelastic codes is not recommended. In this case, a combination of empirical and explicit inelastic methods is recommended.

The most efficient and reliable design for this class would usually result from a combined application of advanced analytical methods (such as explicit inelastic) with conventional methods (such as empirical methods)."

For significant complexity, they suggest that:

"Application of elastic and implicit inelastic models is generally not recommended unless significant calibration data exists for exactly the same condition under study, both in terms of stress and geometry.

An explicit inelastic model, which incorporates advanced failure criterion, is currently the only reliable tool that can be applied to this class of problems."

Most practitioners understand that all rock masses are complex (particularly in mining where orebody genesis usually results in disturbance, alteration etc.). Based on the above recommendations one might conclude that only the most complex, sophisticated models should be used for virtually any analyses. However, what is often being overlooked is the fact that the foremost deciding factor in the selection of constitutive behaviour must be the available data (quality, quantity, uncertainty etc.). Over the last decade or so there has been a shift in modelling philosophy to assume that because we have the computing power to incorporate high degrees of complexity that this must be 'correct', and the underlying limitations and 
uncertainty are often forgotten. It is easy to over sell the capabilities of complex, non-linear models, particularly to clients who do not understand the limitations and uncertainties involved. In modelling, however, it is always helpful to remember the quote from Einstein that "things should be kept as simple as possible but not simpler."

It is a common misconception that simplified constitutive models are fundamentally flawed due to their inability to mechanically replicate complex material behaviour. Figure 10 shows a comparison of $\sigma_{1}$ results for elastic (Figure 10(a)) versus non-elastic (Figure 10(b)) results for a particular mining simulation. It is clear that the discrete computer output for the two simulations are incompatible, leaving the impression that one of the models is wrong. Interpretation of both model outputs by a qualified geomechanics practitioner (Figure 10(c)), however, indicates that the two final interpretations are, in this case, very close. With modern computing capacity and user-friendly software, a critical issue in the practice of numerical modelling is the knowledge level and experience of the individual conducting the simulations and interpretation.

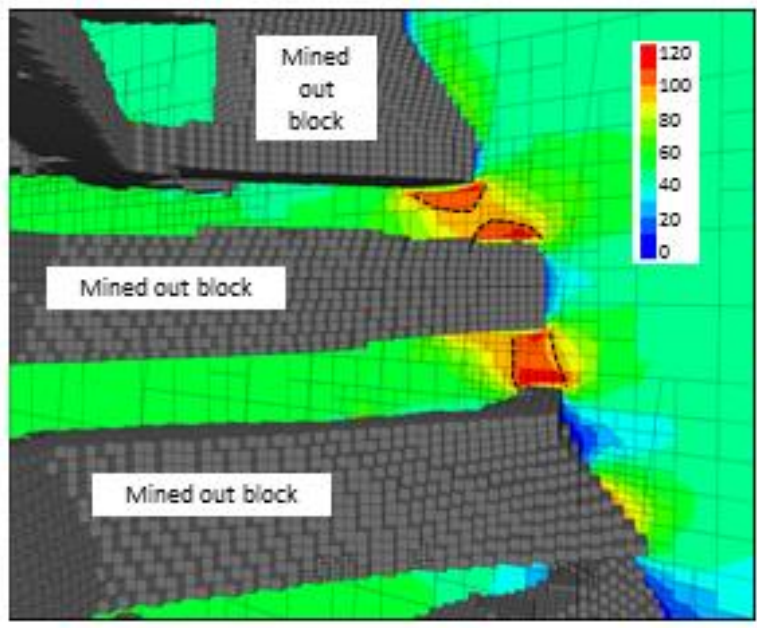

(a) Contour major principal stress as predicted by a calibrated elastic model plotted on a vertical cross-section through adjacent sill pillars. The extent of predicted yield is defined by the relationship $\sigma_{1}=0.8 \mathrm{UCS} \approx 90 \mathrm{MPa}$.

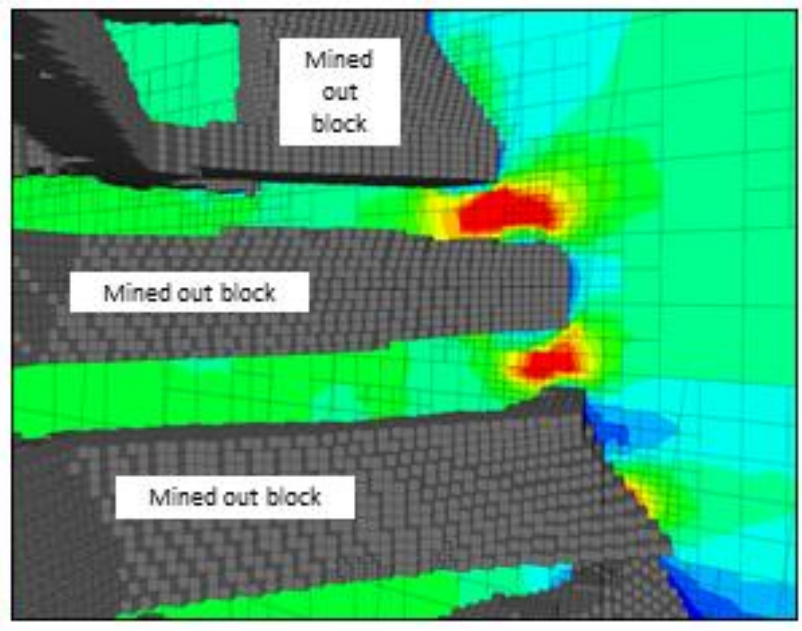

(b) Contour major principal stress as predicted by a calibrated plastic strain softening model plotted on vertical cross-section through adjacent sill pillars. The extent of predicted yield for is defined by yielded elements (below centre).

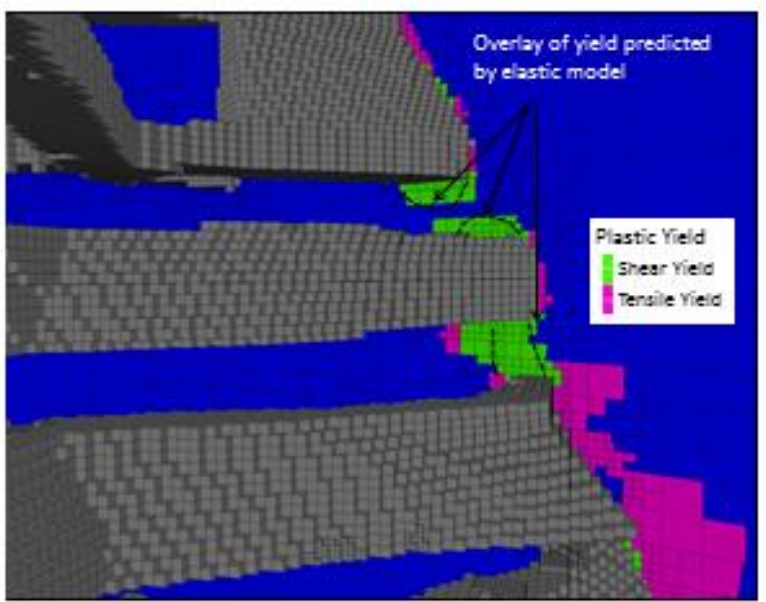

(c) The extent of yield predicted by calibrated linear-elastic and non-linear plastic models is nearly identical despite explicit variation between the stress predicted by both models.

Figure 10 Comparison of elastic and $n$-elastic model output and interpretation

The fundamental issue is that in mine-scale, data-limited situations, 'all model results are wrong'. Considering the data-limited nature and complex geomechanical conditions typical of mining applications, we should never expect absolutely correct answers - these are models, not reality. What should be 
expected is a reasonable representation of reality, based on simulated complexity which is suitable to the available data. What should be demanded by the end user is the use of the most appropriate level of modelling for the situation in question (e.g. PEA, pre-feasibility, feasibility, final design), and considering the level of available input data (number and type of boreholes, underground access, laboratory testing, instrumentation etc.). The presentation of model results and interpretation must include a clear definition of the model assumptions, limitations and the inherent uncertainty and risk.

Modern numerical stress analysis and the recent increases in computational capability that facilitates it, represent probably the most powerful tools available to geomechanics practitioners today. These tools, however, come with high degrees of uncertainty that often go unrecognised and are not a license to:

- Turn off your brain.

- Not to routinely go underground to conduct mapping and make critical observations on ground and support behaviour to test model output with.

Model output also needs to be subject to routine gut checks. For example, if a model suggests that an unusually large underground opening will be stable, this should be tested against simple empirical tools such as the stability or caving graphs. If significant discrepancy exists between the two predictions do not simply discard the empirical tool with the arrogant assumption that it is not applicable in this complex case. Rather search for what may be missing, or misrepresented, in the numerical model input, e.g. inadequately defined critical structures etc. Many projects have failed physically and economically due to the hubris of practitioners who believe that highly sophisticated, complex models and their associated compelling graphics must be correct. It is imperative that we educate practitioners and managers as to the uncertainties and associated risks involved with such models.

\subsection{Backfill}

Most modern mines utilise backfill. The advantages of backfill are numerous, including:

- Regional ground support.

- Waste rock disposal.

- Safe disposal of acid generating waste.

- Optimising total reserve extraction.

- Minimising tailings management facilities.

There are four common backfill types: rockfill, cemented rockfill, cemented hydraulic tailings fill (CHF) and cemented paste fill (CPB). All four fill types are appropriate depending on mine specific circumstances and may be used in combination.

Both CHF and CPB are delivered underground in a fluid (Newtonian or non-Newtonian), form and require that undercut accesses are barricaded to contain the fill (Figure 11). Both fill types contain binding agents that set up over time and transform the fill from a fluid to a solid. Critical aspects with the use of CHF and CPB concern wall stability when mined against, back stability when undermined, and barricade stability during filling. 


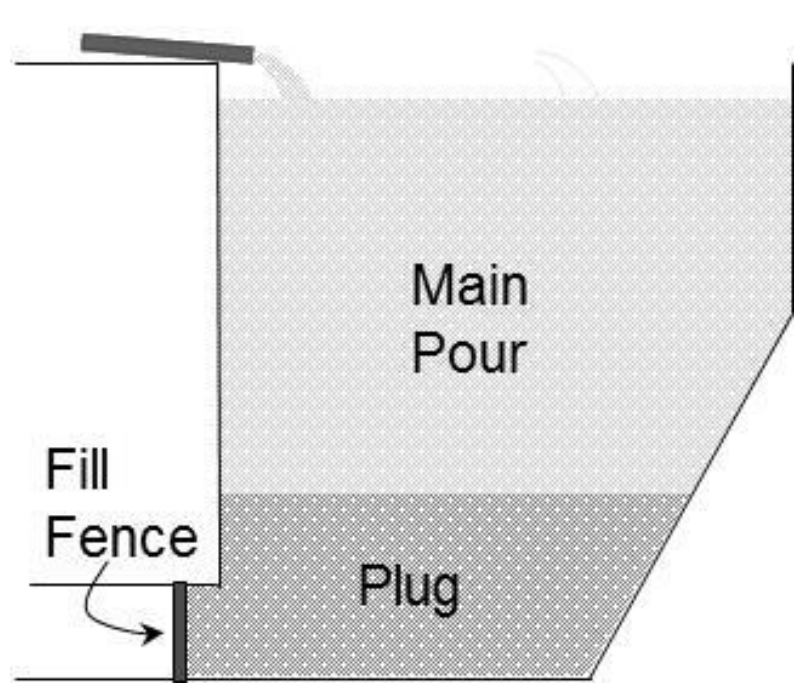

Figure 11 Paste or hydraulic fill barricade

Barricades are normally engineered structures composed of shotcrete and steel reinforcement (i.e. rebar and mesh) and are normally, but not always, arched. Barricades are pressure rated using conventional structural engineering codes based on assumed fluid loading. Commonly, an initial plug of limited height, e.g. 1-2 $\mathrm{m}$ above the access brow, is poured and allowed to reach initial set-up (3-7 days) prior to pouring the remainder of the void, i.e. the main pour. A number of recent field and laboratory research studies (Grabinsky 2010) have shown that in many cases barricade pressures stop increasing well before the end of the plug pour. Research has additionally shown that simple field instrumentation coupled with real-time monitoring can be used to allow continuous fill pours, avoiding the lost time associated with plug set-up. The plug-main pour system has a significant impact on stope sequencing plus additional operating costs associated with stopping and re-starting pours. The efficacy of continuous fill pours has been clearly demonstrated and a number of operations have adopted this technique. Research has also shown, however, that variance in tailings chemistry, processing additives etc. can significantly impact fill set-up time (Thompson et al. 2011); hence, caution must be emphasised. It is imperative that if continuous fill pours are to be contemplated, appropriate real-time barricade monitoring be implemented and used to control the pour. An additional concern relates to barricade pressure ratings. Recent research (University of Toronto, unpublished) suggests that most barricade pressure ratings are extremely over conservative. Research is presently ongoing on this area.

To date barricade instrumentation has been done on a largely research basis. Off the shelf instrumentation that is simple to employ and highly reliable needs to be developed such that the industry can put the excellent research work that has been conducted to routine productive use to help optimise stoping productivity.

\section{Conclusion}

The data-limited nature of mining geomechanics problems often result in high degrees of uncertainty in design analysis. Greater uncertainty results in application of higher safety factors and resulting costs.

In producing operations, scanning systems (photogrammetric or laser) allow much improved geotechnical data collection. These systems, however, do not solve the fracture surface characterisation issue. In underground operations, the very limited data on fracture persistence introduces another significant uncertainty.

In pre-production, while borehole camera and various televiewer systems allow improved data collection, the limitation remains with the number and density of geotechnical borings. Uncertainty in pre-production analysis is therefore generally very high and can significantly impact project feasibility. 
Rock mass characterisation remains tied to classification systems developed in the 1970s and 1990s. These systems are subject to the inherent uncertainties in the data collection methods described previously and inject additional uncertainty in their application.

Hard rock empirical design methods, largely developed in the 1980s and 1990s, are mature tools. Although these can always be improved through the addition of more case studies, their applicability in future very deep, high stress applications is uncertain. In all cases, empirical design methods should be field fitted (calibrated) for the specific site conditions where suitable data is available to do so (generally only possible for relatively mature mines).

Instrumentation, both seismic and conventional, has improved considerably and continues to evolve. Wireless communication systems now make widespread use of conventional instrumentation both practical and cost-effective. Such systems, however, are still not being used to their maximum effect. Part of the problem rests in making such systems sufficiently robust to survive hostile mining environments with minimal maintenance.

Numerical modelling capabilities have undergone nothing less than a revolution powered by the exponential increase in computational power since the introduction of personal computers in the 1980s. While these models provide analysis capabilities unimaginable only a few decades ago, the data-limited nature of geomechanical problems result in high levels of uncertainty in model output, particularly for the more complex models, unless these can be rigorously calibrated. This limitation of numerical modelling is generally poorly understood by the general mining community.

In the near term, a direct linkage of real-time monitoring to numerical modelling allowing ongoing near real-time calibration should result in a reduction in uncertainty in numerical model results. While this would be an advantage for producing operations, it will not help in pre-production, e.g. PEA, pre-feasibility, feasibility, studies. It would appear that in pre-production situations nothing less than a step change breakthrough in drilling efficiency or possibly in geophysical techniques will allow significant reduction geomechanical analysis uncertainty.

As described earlier, while empirical design methods, instrumentation and particularly numerical modelling have undergone transformational change over the past 35-40 years, with the exception of the introduction of scanning technologies there has been very little advance in geotechnical data collection techniques. Additionally, model parameterisation is directly tied to empirical rock mass classification techniques. The result is that our modelling capabilities now vastly exceed our ability to quantitatively characterise fractured rock masses and parameterise design models. The failure to recognise the high level of inherent uncertainty in many, if not most, geomechanical analyses can arise as an unforeseen fatal flaw in high level corporate decision-making.

\section{Acknowledgement}

I acknowledge the assistance of Dr K Kalenchuk of Mine Design Engineering and Mr A Dulmage of Mine Design Technologies in providing reviews and edits of this manuscript.

\section{References}

Barton, NR, Lien, R \& Lunde, J 1974, 'Engineering classification of rock masses for the design of tunnel support', Rock Mechanics, vol. 6 , no. 4, pp. 189-239.

Bawden, WF 2010, 'Thoughts on quantitative field scale characterization of post-failure rock mass conditions and their influence on underground mine design', Proceedings of the 44th US Rock Mechanics Symposium and the 5th US-Canada Rock Mechanics Symposium, American Rock Mechanics Association, Minneapolis, vol. 2, pp. 855-870.

Bieniawski, ZT 1973, 'Engineering classification of jointed rock masses', Transactions of the South African Institution of Civil Engineers, vol. 15, no. 12, pp. 335-344.

Bieniawski, ZT 1976, 'Rock mass classification in rock engineering', in ZT Bieniawski (ed.), Exploration for rock engineering: proceedings of the symposium on exploration for rock engineering, A.A. Balkema, Lisse, pp. 97-106.

Brady, BHG \& Brown, ET 1985, Rock mechanics: for underground mining, Allen \& Unwin, London. 
Brady, T, Martin, L \& Pakalnis, R 2005, 'Empirical approaches for opening design in weak rock masses', Mining Technology, vol. 114, no. 2, pp. 13-20.

Clark, LM \& Pakalnis, RC 1997, 'An empirical design approach for estimating unplanned dilution from open stope hangingwalls and footwalls', Proceedings of the CIM 99th Annual General Meeting, Canadian Institute of Mining, Metallurgy and Petroleum, Westmount, Quebec.

Crockford, AM, Kalenchuk, KS \& Bawden, WF 2015, 'Calibration of inelastic constitutive behaviour at a late stage mine and the problems associated with data limited calibration', Proceedings of the 49th US Rock Mechanics/Geomechanics Symposium, American Rock Mechanics Association, Minneapolis, 8 p.

Crowder, JJ, Coulson, AL \& Bawden, WF 2006, The field-scale rock mechanics laboratory: estimation of post-peak parameters and behaviour of fractured rock masses, Proceedings of the 41st US Symposium on Rock Mechanics (USRMS), American Rock Mechanics Association, Minneapolis, $12 \mathrm{p}$.

Deere, DU 1964, 'Technical description of rock cores for engineering purposes', Rock Mechanics and Engineering Geology, vol. 1, no. 1 , pp. 17-22.

Grabinsky, M 2010, 'In situ monitoring for ground trothing cemented paste backfill designs', in RJ Jewell \& AB Fourie (eds), Proceedings of the 13th International Seminar on Paste and Thickened Tailings (Paste 2010), Australian Centre for Geomechanics, Perth, pp. 85-98.

Grimstad, E \& Barton, N 1993, 'Updating the Q-system for NMT', in C Kompen, SL Opsahl \& SL Berg (eds), Proceedings of the International Symposium on Sprayed Concrete, Norwegian Concrete Association, $21 \mathrm{p}$.

Hedley, DGF \& Grant, F 1972, 'Stope and pillar design for the Elliot Lake uranium mines', Bulletin of the Canadian Institute of Mining and Metallurgy, no. 65, pp 37-44.

Hoek, E 2007, Practical rock engineering, Rocscience, viewed 1 July 2015, https://www.rocscience.com/documents/hoek/ corner/Practical-Rock-Engineering-Full-Text.pdf

Hoek, E \& Brown, ET 1980, 'Underground excavations in rock', Institution of Mining and Metallurgy, London.

Hoek, E, Kaiser, PK \& Bawden, WF 1995, Support of underground excavations in hard rock, A.A. Balkema, Rotterdam.

Holling, CS (ed.) 1978, Adaptive environmental assessment and management, John Wiley \& Sons, Chichester.

Hutchinson, DJ \& Diederichs, MS 1996, Cablebolting in underground mines, BiTech Publishers.

Laubscher, DH 1977, 'Geomechanics classification of jointed rock masses - mining applications', Transactions of the Institute of Mining and Mettalurgy, vol. 86, pp. 1-8.

Laubscher, DH 1984, 'Design aspects and effectiveness of support systems in different mining conditions', Transactions of the Institution of Mining and Metallurgy, vol. 93, no. 10, pp. 70-81.

Lauffer, H 1958, 'Gebirgsklassifizierung fur den Stollenbau', Geololgie und Bauwesen, vol. 24, no. 1, pp. 46-51.

Lunder, P \& Pakalnis, RC 1997, 'Determination of the strength of hard rock pillars', Bulletin of the Canadian Institute of Mining, Metallurgy and Petroleum, vol. 90, no. 1013, pp. 51-55.

Malan, F 2015, 'Hard rock tabular excavations: historic solutions and future challenges', Proceedings of the 13th International Congress of Rock Mechanics.

Mawdesley, C, Trueman, R \& Whiten, W 2001, 'Extending the Mathews stability graph for open stope design', Mining Technology, vol. 110, pp. 27-39.

Moore, E 2014, 'Technology: underground networks - communication skills', Bulletin of the Canadian Institute of Mining, Metallurgy and Petroleum, February issue.

Pakalnis, R, Caceres, C, Clapp, K, Morin, M, Brady, T, Williams, T, Blake, W \& MacLaughlin, M 2005, 'Design spans - underhand cut and fill mining', Proceedings of the 107th CIM-AGM, 9 p.

Potvin, Y 1988, 'Empirical open stope design in Canada' PhD thesis, University of British Columbia.

Salamon, MDG \& Munroe, AH 1967, 'A study of the strength of coal pillars', Journal of the South African Institute of Mining and Metallurgy, vol. 68, pp. 55-67.

Thompson, BD, Bawden, WF \& Grabinsky, MW 2011, 'In situ measurements of cemented paste backfill at the Cayeli Mine', Canadian Geotechnical Journal, vol. 49, no. 7, pp. 755-722.

Vakili, A, Albrecht, J \& Sandy, M 2014, 'Rock strength anisotropy and its importance in underground geotechnical design', Proceedings of the Third Australasian Ground Control in Mining Conference (AusRock 2014), The Australasian Institute of Mining and Metallurgy, Melbourne, pp. 167-180. 
The expanding impact of technology on underground geomechanical mine design

WF Bawden and operations - advances, limitations and future needs 